\title{
HARBOR RESONANCE: A COMPARISON OF FIELD MEASUREMENTS TO NUMERICAL RESULTS
}

\author{
Xiuying Xing ${ }^{1}$, Jiin-Jen Lee ${ }^{2}$, Fredric Raichlen ${ }^{3}$
}

\begin{abstract}
Wave induced oscillation at Bay of Fundy has been studied using a numerical model. From the response characteristics obtained it is seen that the fundamental mode of oscillation at the Bay of Fundy region coincides with the tidal period. The resonant mode of oscillation at the tidal period (12.42 hr) helps explain why Bay of Fundy has the largest tidal range in the world. The numerical results compared well with the tidal records at thirteen tide gauge stations in Bay of Fundy. Discussion also includes numerical results and field measurements at Crescent City harbor and at Los Angeles/Long Beach harbor to show the relationship of the characteristic length of the harbor basin with the resonant periods computed and measured. It is found that the resonant phenomena at these three harbors occurred on normal days although they are very different in size.
\end{abstract}

Keywords: Harbor Resonance; Resonant mode; Wave Induced Oscillation; Long Wave; Bay of Fundy

\section{Introduction}

Bay of Fundy, located between the Provinces Nova Scotia and New Brunswick in Canada as shown in Figure 1 is well known for having the largest tidal range in the world. Approximately 100 billion tons of water flushes in and out the bay twice a day. The dominant tide is the Principal lunar M2 tide, with a period of $12 \mathrm{hr}$ and $25 \mathrm{~min}$ or $12.42 \mathrm{hr}$. When the moon is full or new, the tide may be as high as 53 feet $(16 \mathrm{~m})$ at the head of the bay. The highest tide level occurs in the south branch Cobequid Bay.

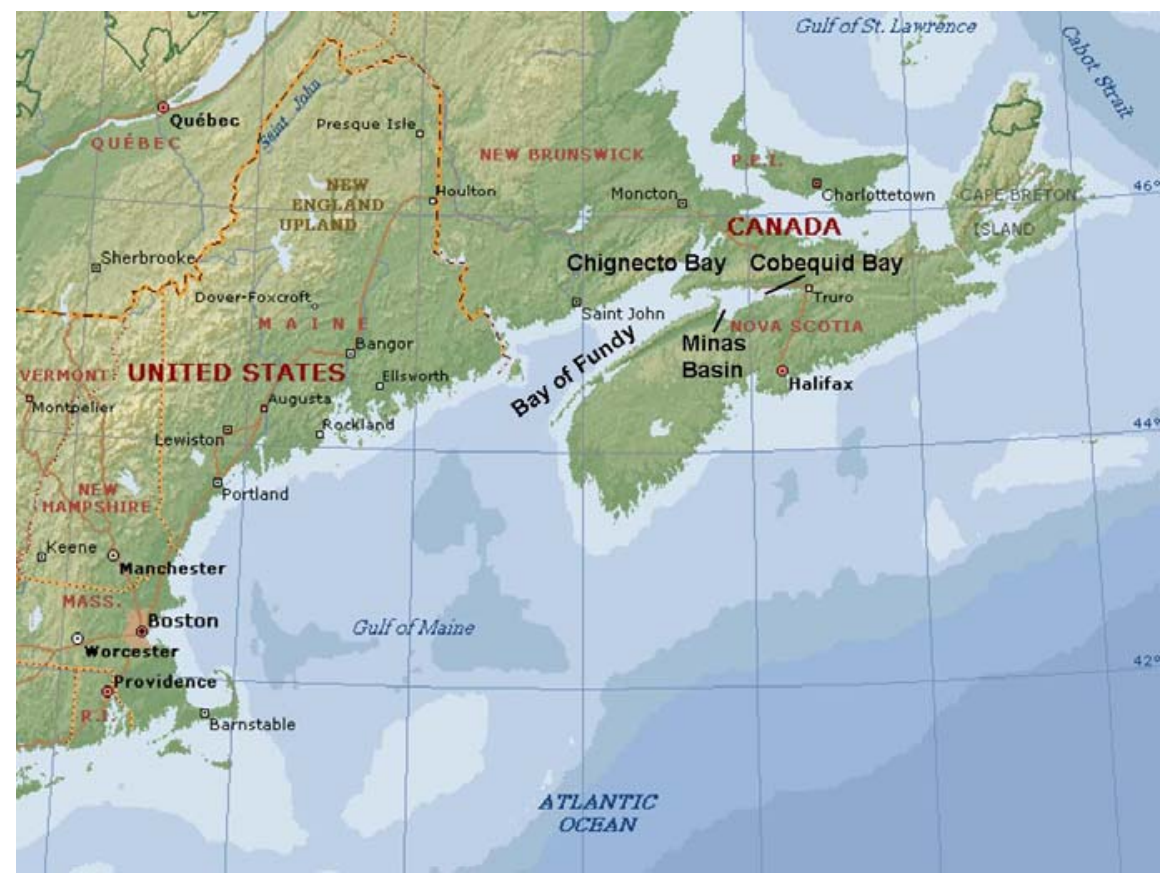

Figure 1. Map of Bay of Fundy and Gulf of Maine.

Why is there such a large tide range in this region? It was first explained as because of the funnel shape of the bay (contraction in width) and the continuously upward slope from the mouth to the head

\footnotetext{
${ }^{1}$ Moffatt \& Nichol Engineers, 3780 Kilroy Airport Way, Long Beach, California, 90808, U.S.A.

${ }^{2}$ Sonny Astani Department of Civil \& Environmental Engineering, University of Southern California, Los Angeles, California, 90089-2531, U.S.A.

${ }^{3}$ Department of Civil and Mechanical Engineering, California Institute of Technology, Pasadena, California, 91125, U.S.A.
} 
(reduction in water depth), the tide is forced to rise. However it was pointed by Marmer as early as in 1922 that even the combination of those two are not enough to produce tides with such enormous ranges. Marmer used the theory of standing waves in a tank to explain the natural resonance in the Bay of Fundy. Several approaches of scales of the bay were used to estimate the natural resonance period of the bay, and the consequent periods obtained ranged from $11.6 \mathrm{hr}$ to $13.0 \mathrm{hr}$. It was concluded that the $12.42 \mathrm{hr}$ tide (M2 tide) is very close to the natural period of oscillation in the Bay of Fundy, which is the primary factor to the tidal phenomena in this area. Later on researchers had continuously worked on this problem to find the natural oscillation period of the bay. Proudman got period of 11.06 hrs with a constant depth approach in 1953 and Rao (1968) found the period to be about 9 hr which only considered the Bay of Fundy alone. With the integration of the Bay of Fundy and Gulf of Maine, the natural period obtained by Garrett (1972) was $13.3 \mathrm{hrs}$. And he modified it to be 12.38 to $12.98 \mathrm{hr}$ in 1974 with a numerical model. The period estimated by Greenberg in 1979 was about 13 hrs.

In this paper, the oscillation periods as well as the wave amplification scale of Bay of Fundy are examined by a frequency domain numerical study and the results are compared with field observations.

\section{Numerical Model and Simulation Results}

The numerical model used here is a hybrid finite element model. The governing equation is the Mild Slope Equation first derived by Berkhoff (1972):

$$
\nabla \cdot\left(C C_{g} \nabla \phi\right)+\frac{C_{g} \omega^{2}}{C} \phi=0
$$

In which $\phi=\phi(x, y)$ is the horizontal variation in velocity potential, $C=\frac{\omega}{k}$ is the wave celerity, $C_{g}=\frac{C}{2}(1+G)=\frac{C}{2}\left(1+\frac{2 k h}{\sinh 2 k h}\right)$ is the group velocity and $G=\frac{2 k h}{\sinh 2 k h}, k$ and $\omega$ are the wave number and the wave frequency, $h$ is the water depth (which is a function of $x$ and $y$ ).

The numerical model incorporates the effects of variable water depth, wave refraction, wave diffraction, wave reflection from partial or fully reflecting boundaries, entrance energy dissipation, as well as wave transmission through porous breakwaters. For a more detail presentation of the numerical model used please see Lee and Xing (2008).

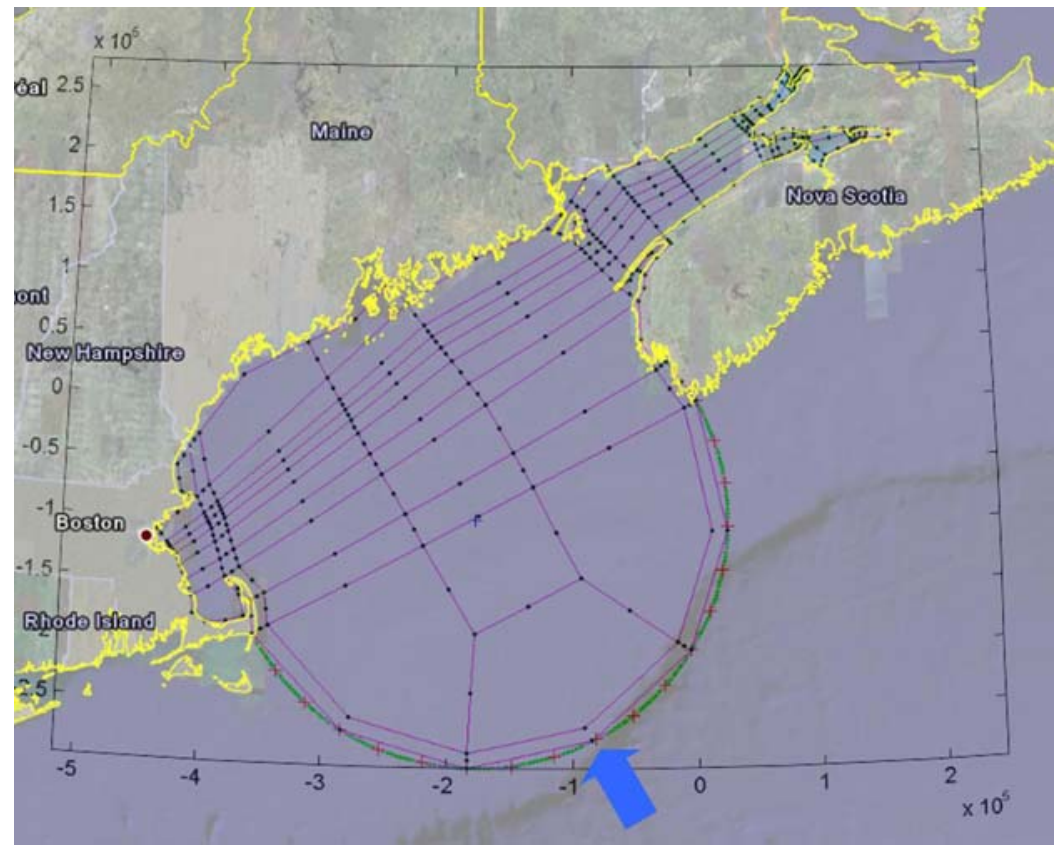

Figure 2. Simulation domain for Bay of Fundy with mesh and incoming wave direction superimposed. 
As shown in Figure 2, the simulation domain includes the Bay of Fundy and the Gulf of Maine. The main blocks of the mesh are superimposed. The model grid contains 77,247 nodes and 18,924 elements. The outside semicircle has a radius of 126.8 miles. The incoming wave direction used in the simulation is illustrated by the arrow outside the semicircle, which is perpendicular to the diameter of the semicircle. Tides are long waves, they will be mostly reflected by the vertical boundary. However considering the natural beach, the reflection coefficient used here for the beach is 0.96 . For the river inlets at the head of the bay, the reflection coefficient is 0.67 with the assumption that some energy will propagate into the rivers.

Ten locations were chosen for the demonstration, which are noted in Figure 3 as 1 to 10. Gauge 1, 2 and 3 are located in the bay, and 4, 5 and 6 are located in the south branch and the other four are located in the north branch.

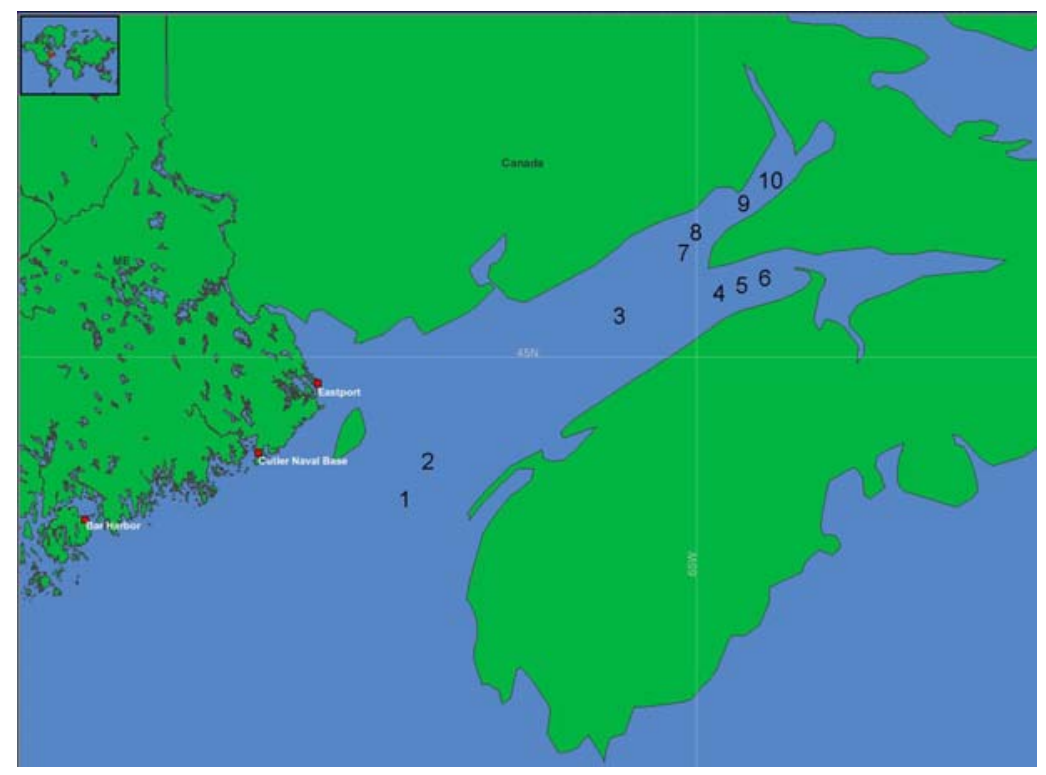

Figure 3. Locations of gauge 1 to 10 selected for the result demonstration.

For a clear comparison, the response curves at gauge 1, 2, 3, 4, 5 and 6 are plotted together in Figure 4 and 1, 2, 3, 7, 8, 9 and 10 are plotted together in Figure 5. The response curves are plotted as amplification factor $R$ (ratio of wave height $H_{r}$ at the indicated location to the incident wave height $H_{i}, R=H_{r} / H_{i}$ ) versus wave frequency $f$. From Figure 4 and 5 , it's seen that the tidal range increases toward the inner region. That is because the $12.42 \mathrm{hr}$ tide is within the first mode of the bay (also called the pumping mode), in which the amplification of wave height increases toward the inner location in the harbor basin. The tide is significantly amplified at the head of the bay area, exactly as found in the field data.

There's another interesting thing shown in the two figures that it seems the peak of the first mode shifts to the right (higher wave frequency or shorter wave period) when the gauges move more inside, roughly from $14 \mathrm{hr}$ to $10 \mathrm{hr}$. But the amplification factor for $12.42 \mathrm{hr}$ tide increases when the gauge moves more inside of the bay. 


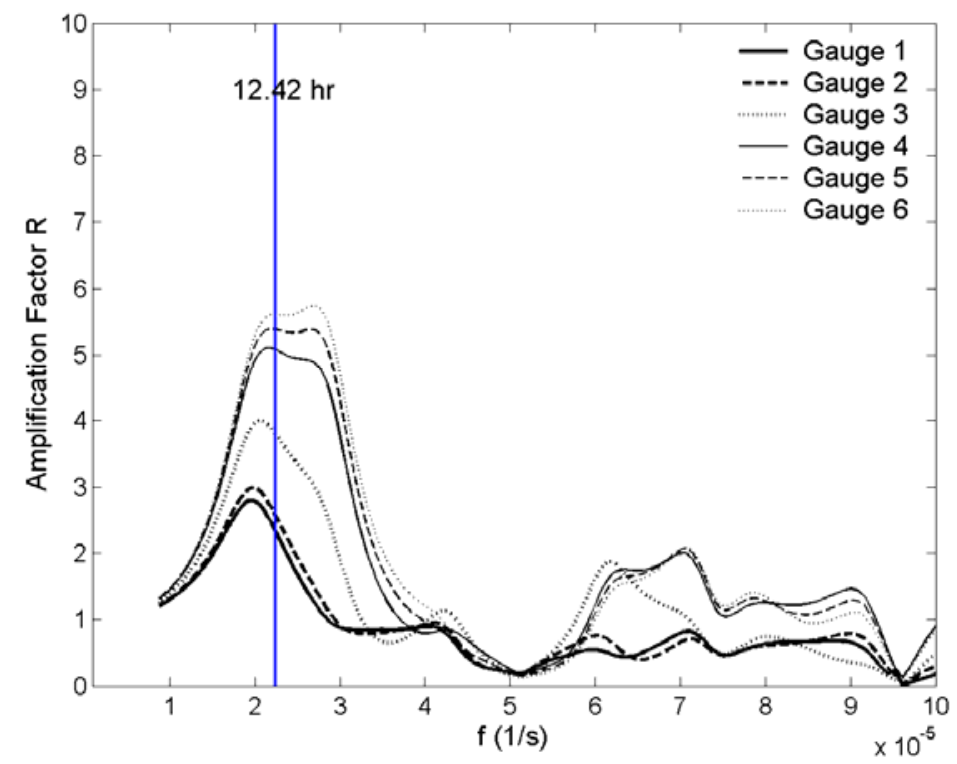

Figure 4. Response curves at gauge 1, 2, 3, 4, 5 and 6.

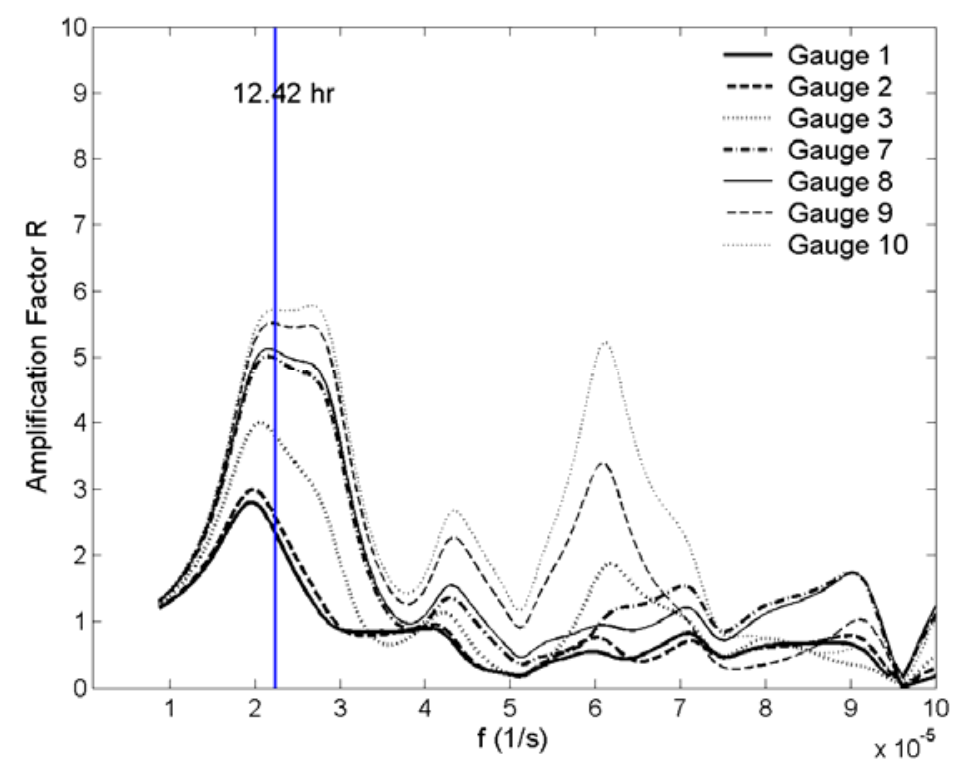

Figure 5. Response curves at gauge 1, 2, 3, 7, 8, 9 and 10.

In order to show how the tide is amplified inside the simulation domain, the modes for the $12.42 \mathrm{hr}$ wave are plotted in Figure 6 and 7. In Figure 6, the distribution of amplification factor is plotted. It's seen that the amplification factor in the Cobequid Bay, located in the south brunch of the bay head, is as high as 8. In fact, the south brunch was observed to have higher tide than the north brunch (Chignetco Bay) as simulated. It was observed that the tide has a height about 4 to $8 \mathrm{ft}$ in the nearshore region outside the Gulf of Maine. The distribution of tide height is plotted in Figure 7 with the assumption that the outside tide is $7.5 \mathrm{ft}$. The corresponding tide in the Cobequid Bay is more than 50 
$\mathrm{ft}$ with the assumption of $7.5 \mathrm{ft}$ tide outside the Gulf of Maine. The tremendous tidal phenomena inside Bay of Fundy are well presented in Figure 7.

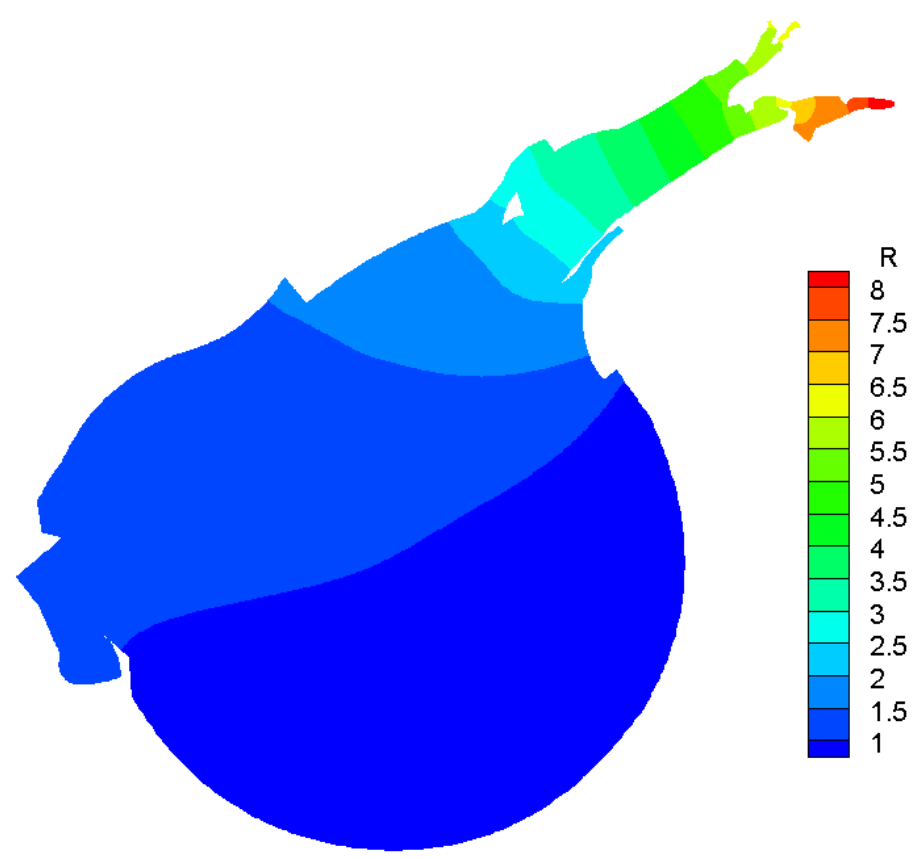

Figure 6. Distribution of amplification factor in the simulation domain.

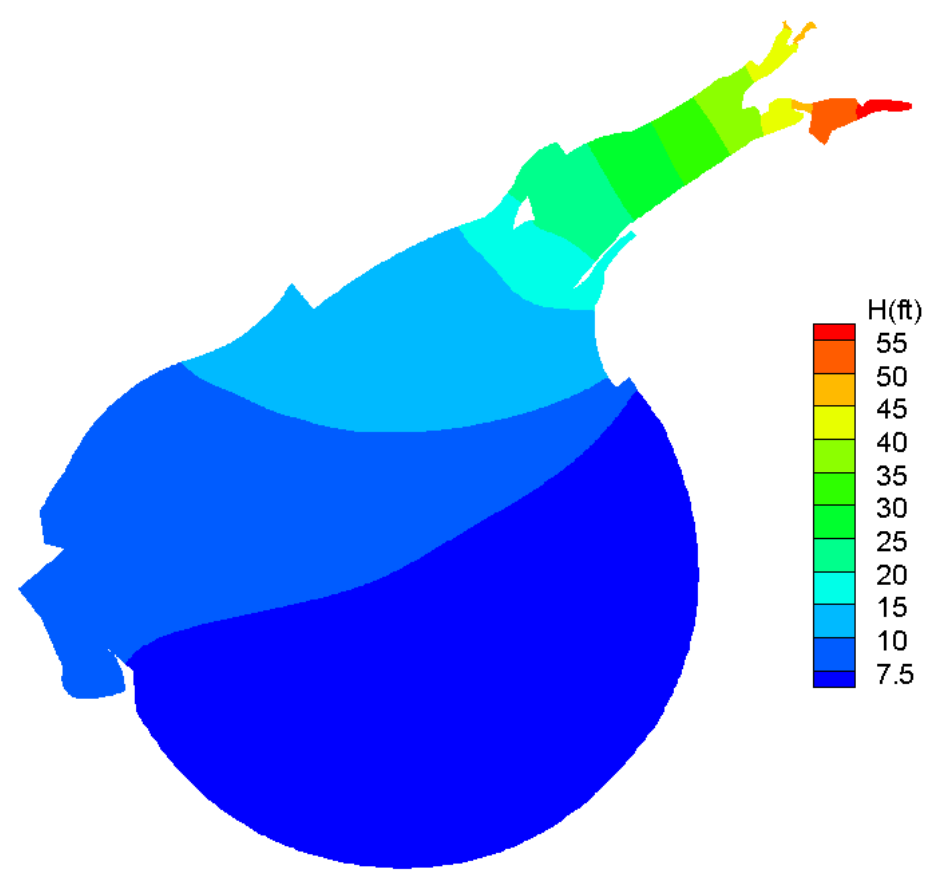

Figure 7. Distribution of tidal range in the simulation domain (assuming that the tidal range outside of Gulf of Maine to be $7.5 \mathrm{ft}$ ). 
Comparing Simulation Results with Field Measurements

Within Bay of Fundy, there exists several tide gauge stations. Some of them have tide records available since the beginning of 2007 (http://www.waterlevels.gc.ca). In order to test the simulation results, 13 tide stations were selected for comparison, as illustrated in Figure 8. The station Outer Wood Island is located approximately at the entrance of the bay, the stations Dipper Harbour West and St. Martins are inside the bay. Stations Baxters Harbour, Scots Bay, Diligent River, Five Islands and Burntcoat Head are in the south branch Cobequid Bay, and the stations Herring Cove, Cape Enrage, Joggins and Hopewell Cape are in the north branch Chignecto Bay.

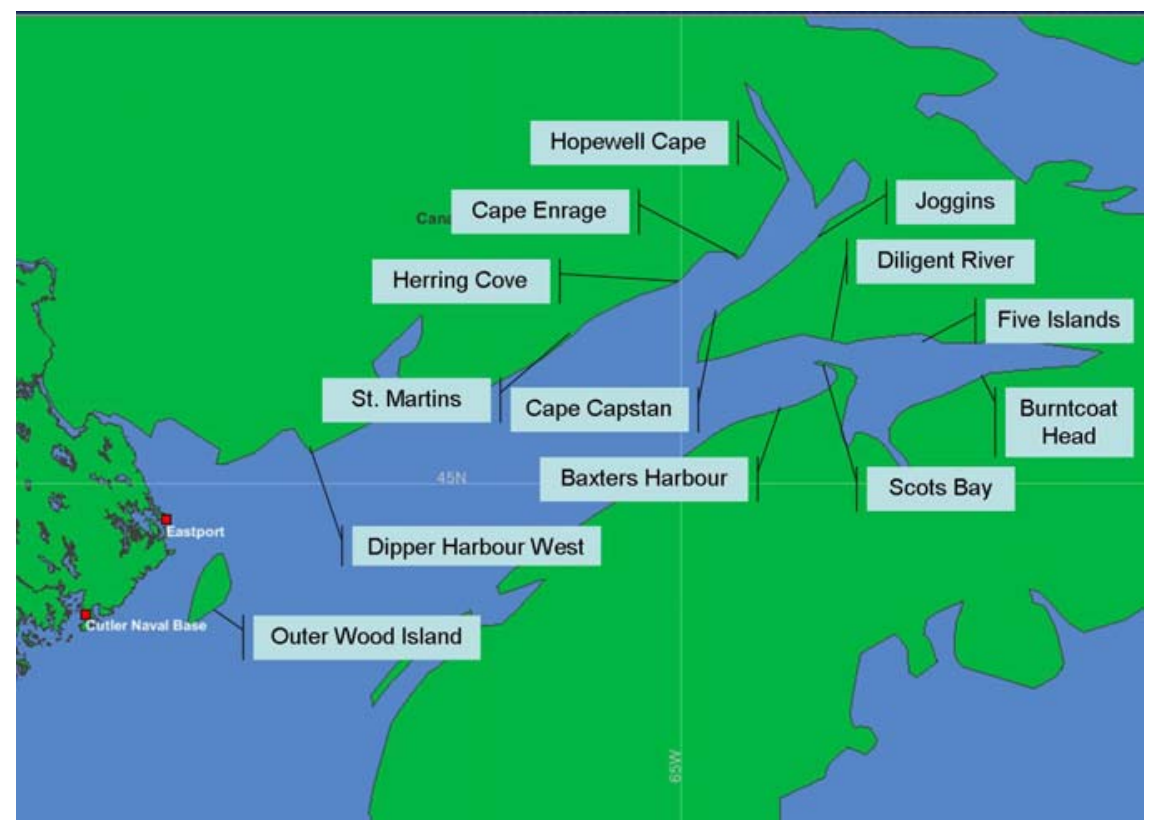

Figure 8. Locations of 13 tide stations in Bay of Fundy.

Since the station Outer Wood Island is very close to the inlet of the bay, it was chosen as the reference point to compute the amplification factor. The tidal ranges at the 13 stations for the four weeks (the first 7 days of August and November in 2007 and February and May in 2008) are normalized by the corresponding tidal ranges at the station Outer Wood Island to get the amplification factors. The averages of the amplification factors in the four weeks, as well as the normalized amplification factors with the same reference point (Outer Wood Island) from the simulation, are obtained and listed in Table 1.

\begin{tabular}{|l|l|c|c|c|}
\hline \multicolumn{2}{|l|}{ Table 1. Comparison between the observed and simulated amplification factors. } \\
\hline & Name of the Gauge & $\begin{array}{c}\text { Observed Amplification } \\
\text { Factor (Normalized by } \\
\text { Outer Wood Island) }\end{array}$ & $\begin{array}{c}\text { Simulated Amplification } \\
\text { Factor (Normalized by } \\
\text { Outer Wood Island) }\end{array}$ & $\begin{array}{c}\text { Difference (\%) } \\
1.00 \\
\end{array}$ \\
\hline 1 & Outer Wood Island & 1.00 & 1.74 & -6.99 \\
\hline 2 & St. Martins & 1.87 & 1.32 & -8.81 \\
\hline 3 & Dipper Harbour West & 1.45 & 2.31 & -1.29 \\
\hline 4 & Baxters Harbour & 2.34 & 2.36 & -0.75 \\
\hline 5 & Scots Bay & 2.37 & 2.46 & -2.68 \\
\hline 6 & Diligent River & 2.53 & 2.86 & 0.78 \\
\hline 7 & Five Islands & 2.84 & 3.07 & 0.94 \\
\hline 8 & Burntcoat Head & 3.04 & 2.10 & -3.13 \\
\hline 9 & Herring Cove & 2.17 & 2.11 & 0.10 \\
\hline 10 & Cape Capston & 2.11 & 2.21 & -0.45 \\
\hline 11 & Cape Enrage & 2.22 & 2.37 & -5.10 \\
\hline 12 & Joggins & 2.50 & 2.42 & -3.91 \\
\hline 13 & Hopewell Cape & 2.52 & & \\
\hline
\end{tabular}


The last column in Table 1 lists the differences between the observed and computed amplification factors. It can be seen that the largest difference is $8.81 \%$ at the station Dipper Harbour west. For other stations the errors are normally less then $5 \%$, which means the modeling is quite reasonable. The simulated amplification factor is generally less than the observed ones. This may be improved by increasing the reflection coefficients at the beach boundary.

As expected, the simulation for Bay of Fundy reveals the fact that the tremendous tidal ranges in this area are not purely caused by the contraction of bay width and the decreasing of water depth, but also because of the coincidence between the periods of semi-diurnal tides and the natural oscillation period of the first resonant mode of the bay. The tides are amplified as much as 8 times at the head of the bay. The 2-D figures clearly show the distribution of amplification factors as well as the distribution of the tidal ranges. The simulated results are also compared with the available tide station records. The agreement between the simulated and observed amplification factors normalized by the data at Outer Wood Island (at the inlet of the bay) proves the accuracy and reliability of the numerical model.

\section{Further Discussion}

It is interesting to look at resonances or oscillations due to long period waves in bays and harbors with different sizes as compared to Bay of Fundy. For example, the Crescent City Harbor region in northern California (shown in Figure 9) and the Los Angeles/Long Beach Harbor (LA/LB Harbor) in southern California (shown in Figure 10), At these harbor basins larger than usual water surface elevations have been observed in response to near field or far field tsunami-genic events.

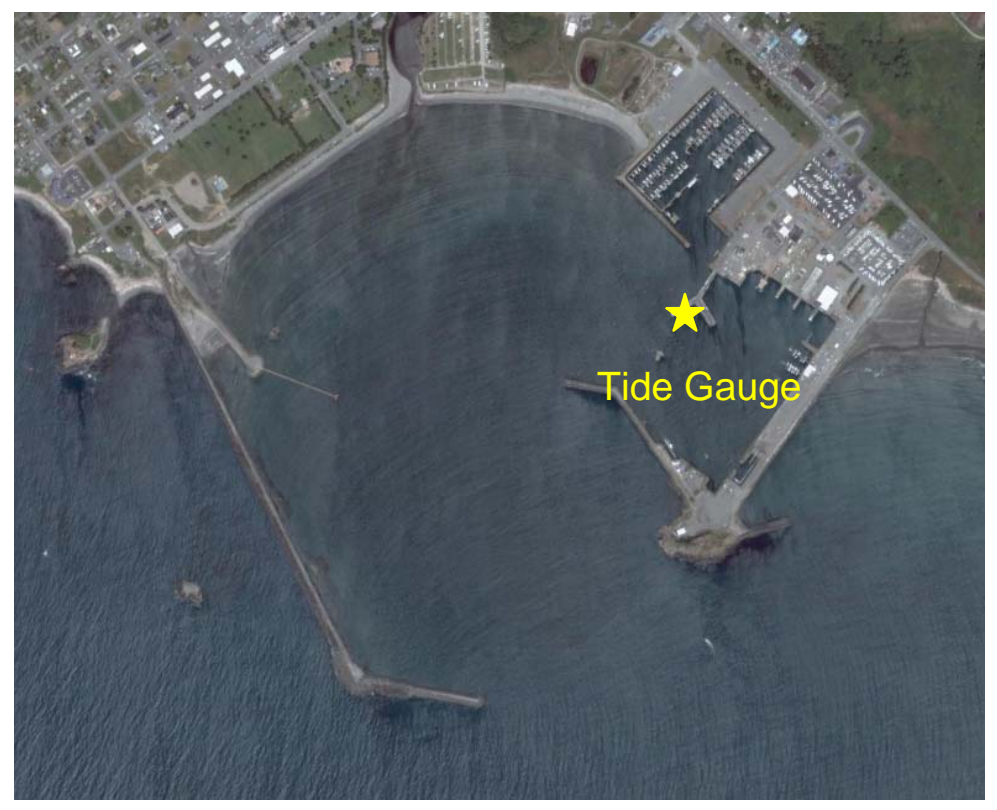

Figure 9. Air photo of Crescent City Harbor with the tide gauge noted. 


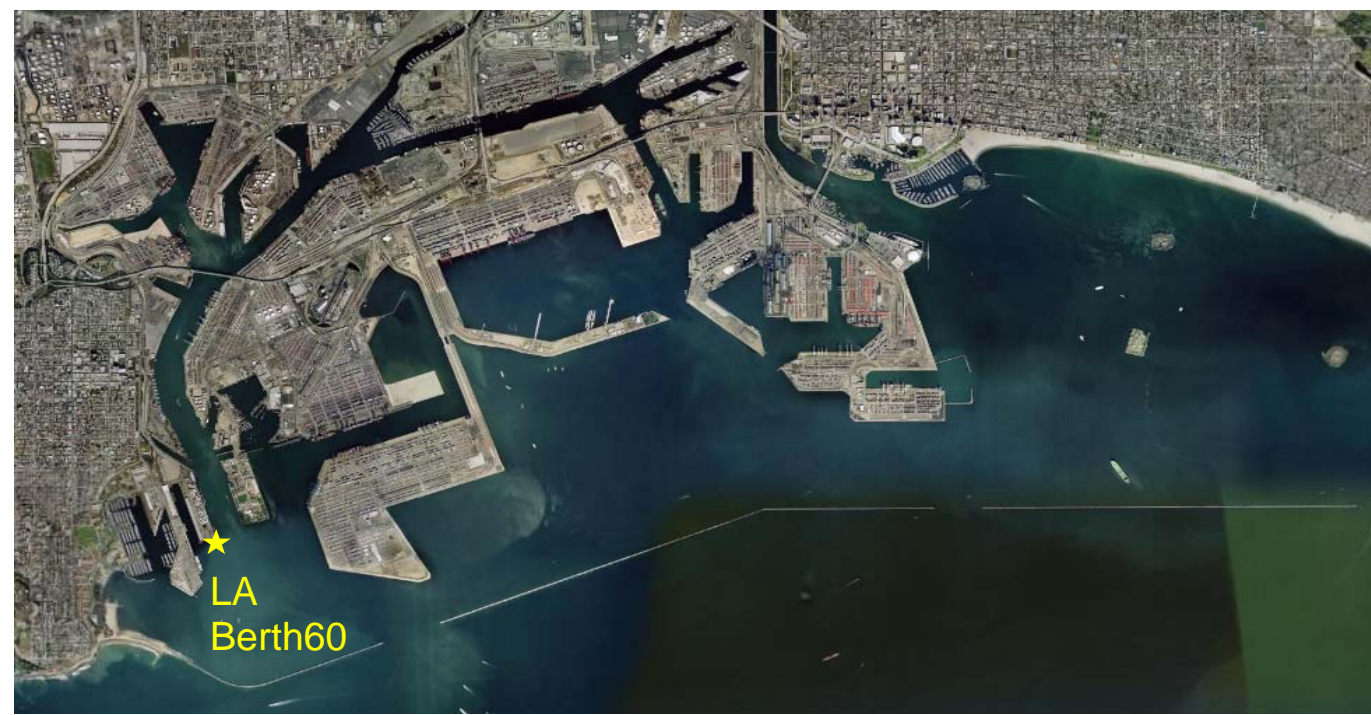

Figure 10. Air photo of Los Angeles/Long Beach Harbor with Tide Gauge LA Berth60 noted.

An examination of the tide record associated with several tsunami events indicates that water levels at the recording stations at Crescent City Harbor and LA/LB Harbor have been amplified from waves originated from near-field as well as that from far-field. The earthquake epicenters (origin of tsunamis) and event times of the recent earthquake-generated tsunami-genic events are illustrated in Figure 11.

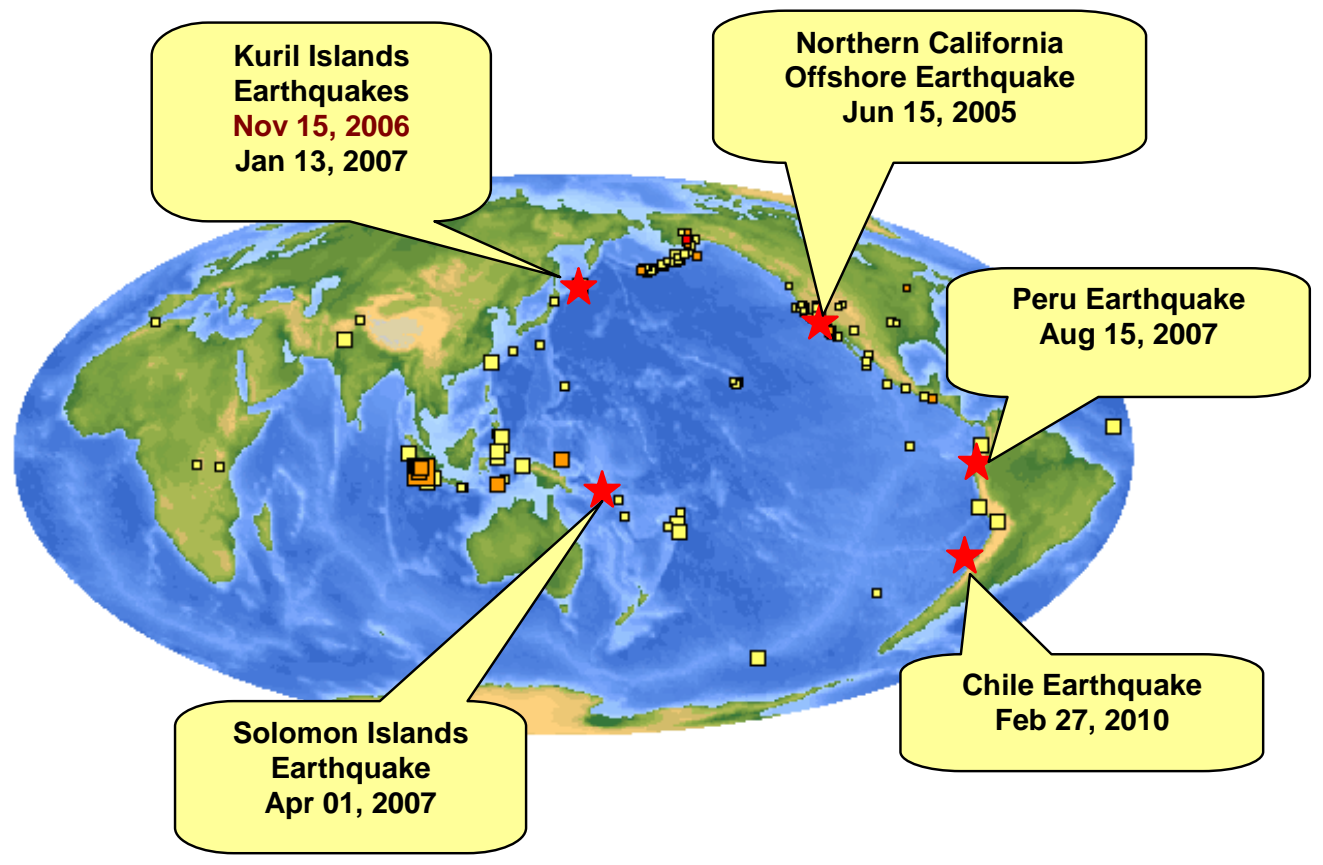

Figure 11. Epicenters and event times of recent earthquakes superimposed on Google Earthquake Map.

Spectrum was obtained for the tide records at the two gauges during these tsunami-genic events, which reveals the energetic waves inside Crescent City Harbor and LA/LB Harbor. Those energetic waves obtained are listed in Table 2. It's seen that the most energetic waves at Crescent City Harbor are all around 21 to 22 minutes, but those at LA/LB Harbor are all near 1 hr, which agreed well with 
the results from similar numerical studies for Crescent City Harbor and LA/LB harbor by the authors (Xing et al, 2008 and Lee et al, 2008). The Crescent City Harbor tide gauge was down during the Solomon Islands earthquake event on April 2007.

Table 2. Energetic Waves obtained from wave spectrum at Crescent City Harbor and LA/LB Harbor during recent tsunami-genic events.

\begin{tabular}{|l|c|c|}
\hline Epicenter and Time & Energetic Wave at Crescent Harbor & Energetic Wave at LA/LB Harbor \\
\hline $\begin{array}{l}\text { North California Offshore } \\
\text { Jun 15, 2005 }\end{array}$ & $22.0 \mathrm{~min}$ & $60.4 \mathrm{~min}$ \\
\hline $\begin{array}{l}\text { Kuril Islands } \\
\text { Nov 15, 2006 }\end{array}$ & $22.0 \mathrm{~min}$ & $69.0 \mathrm{~min}$ \\
\hline $\begin{array}{l}\text { Kuril Islands } \\
\text { Jan 13, 2007 }\end{array}$ & $21.5 \mathrm{~min}$ & $62.6 \mathrm{~min}$ \\
\hline Solomon Islands & N/A & $51.0 \mathrm{~min}$ \\
Apr 01, 2007 & & $60.2 \mathrm{~min}$ \\
\hline Peru & $21.0 \mathrm{~min}$ & $62.4 \mathrm{~min}$ \\
Aug 15, 2007 & & $73.3 \mathrm{~min}$ \\
\hline Chile & $22.0 \mathrm{~min}$ & $70.0 \mathrm{~min}$ \\
Feb 27, 2010 & & $66.9 \mathrm{~min}$ \\
& & $52.6 \mathrm{~min}$ \\
\hline
\end{tabular}

Further examination on the water surface elevation records during normal days at the Crescent City Harbor and LA/LB Harbor was performed. Wave oscillation condition in the three month May, June and July of 2008 at the tide gauges in the Crescent City Harbor and LA/LB Harbor are analyzed, and the wave spectrum is plotted in Figure 12 and 13 respectively. The colored contours demonstrate the distribution of wave energy contained in different frequencies during these 3 month period.

In Figure 12, the red band at the bottom indicates the high energy contained in tide. Beside the tide, the 22 minute wave is clearly shown in the spectrum. It's very apparent that the 22 minute wave always oscillates inside Crescent City Harbor.

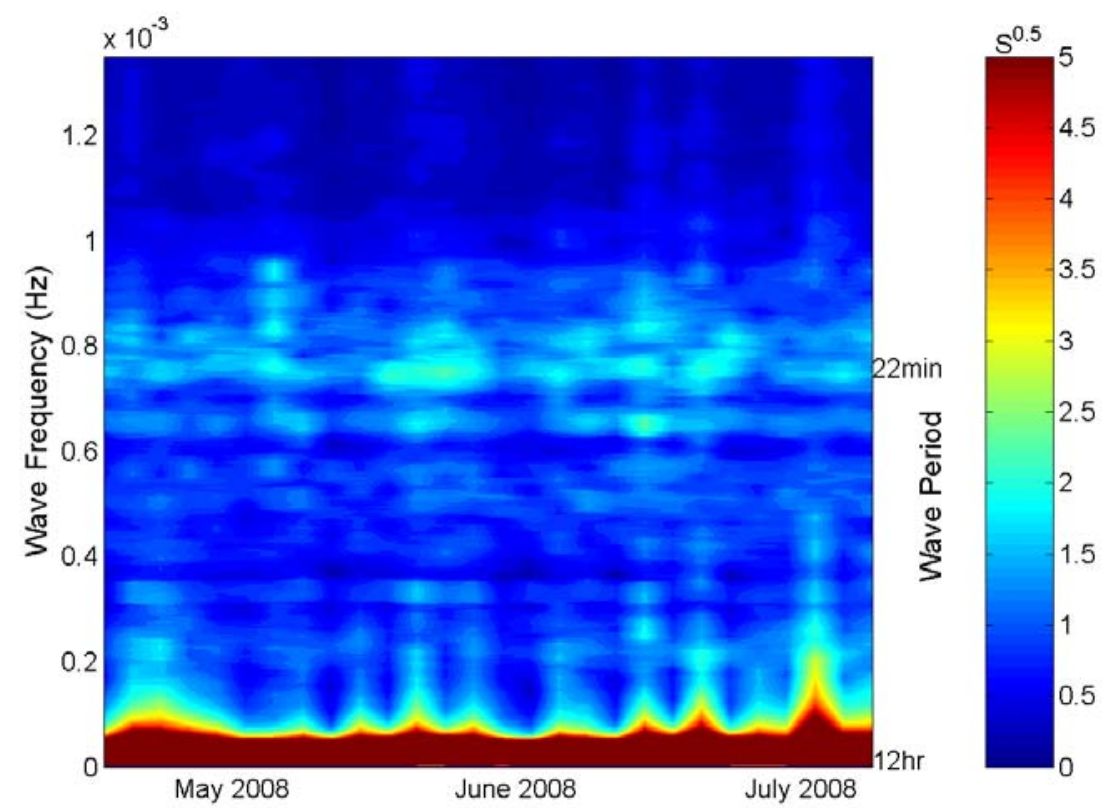

Figure 12. Wave Spectrum at the tide gauge station in Crescent City Harbor during May, June and July, 2008.

Similar spectrum obtained from the tide gage station at Berth 60 in Los Angeles Harbor, CA is shown in Figure 13 for the same three months period. From Figure 13 it is seen that at LA/LB Harbor the resonant period of about $1 \mathrm{hr}$ existed. The fact that the predominate resonant wave period at LA/LB Harbor is so different from Crescent City Harbor further proves that the oscillation waves inside a harbor are of local response and are determined by the harbor itself. 


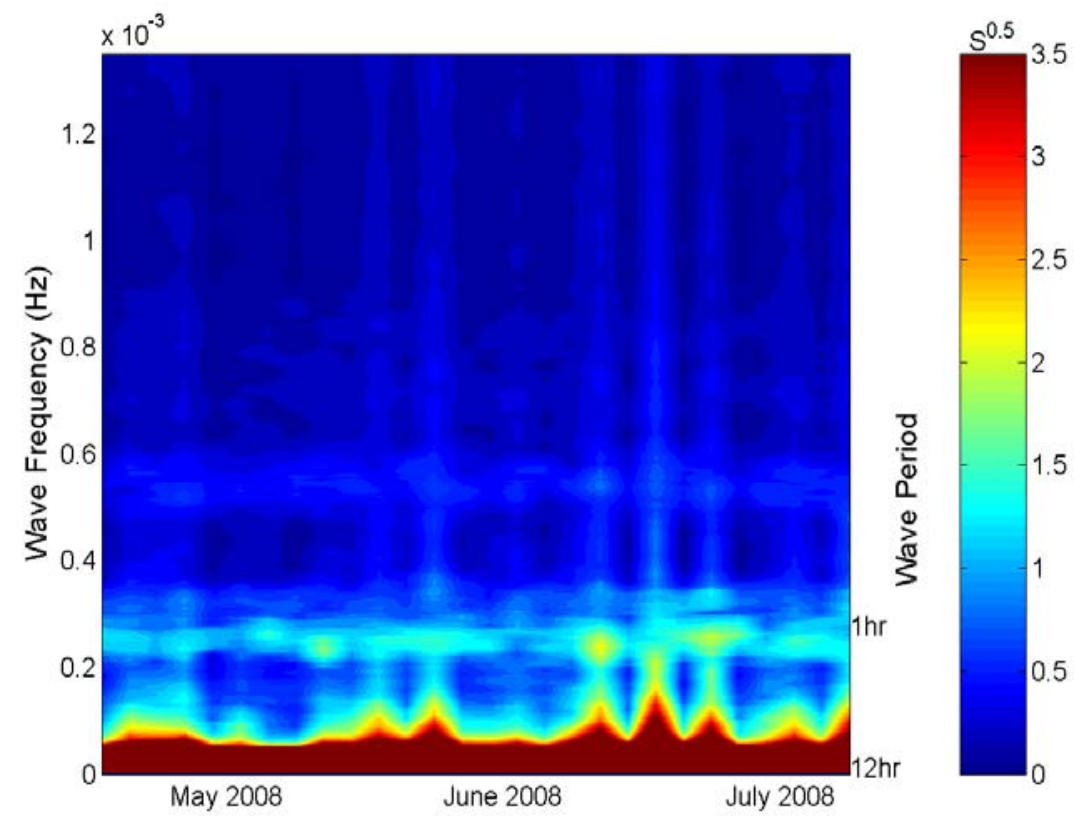

Figure 13. Wave Spectrum at the tide gauge station LA Berth 60 in LA/LB Harbor during May, June and July, 2008.

The time series of the water level and the corresponding wave spectrum at these tide gauge stations on a single day (July 21, 2008) were also plotted for demonstration. The water level time series and it's spectrum at Crescent City Harbor are shown in Figure 14 and 15 and those at L.A. Berth 60 are shown in Figure 16 and 17 respectively. These figures reveal the fact that as long as there exists a wave in the incident wave group which has a period within the first resonant mode range, it will be amplified and contain more energy and they are manifested through spectral density curves.

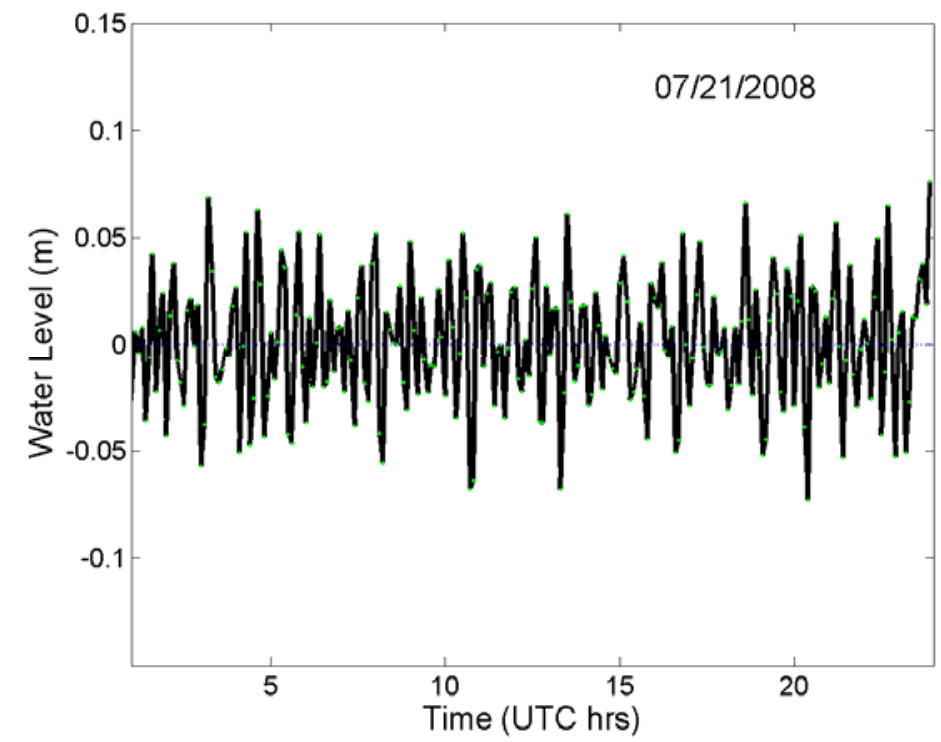

Figure 14. Water level (with the tide removed) at the tide gauge station in Crescent City Harbor on July 21, 2008. 


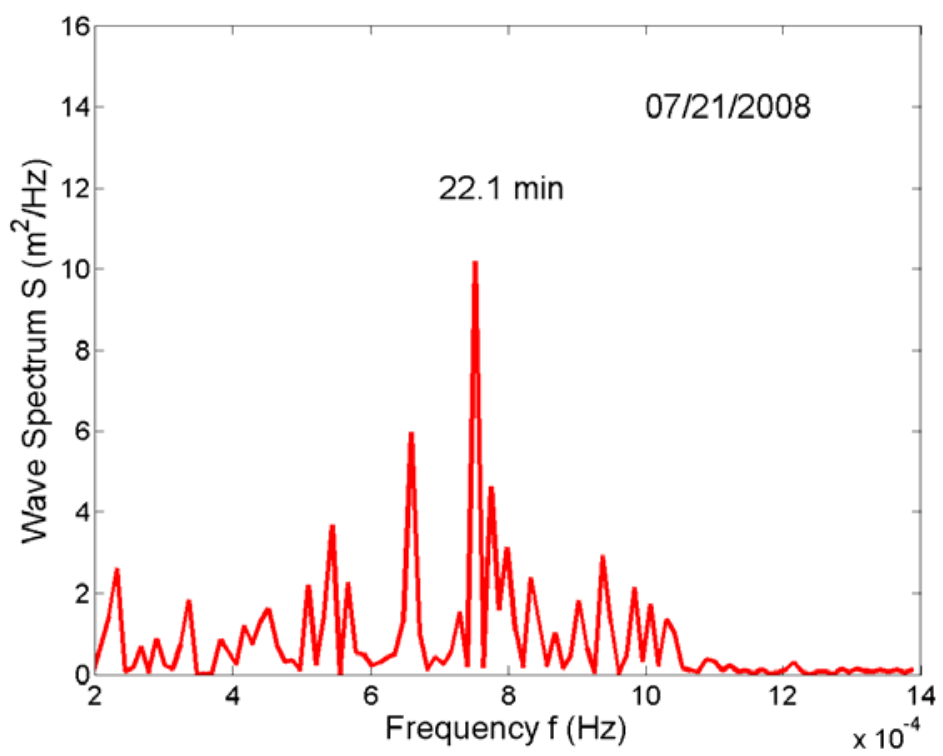

Figure 15. Wave spectrum at the tide gauge station in Crescent City Harbor on July 21, 2008.

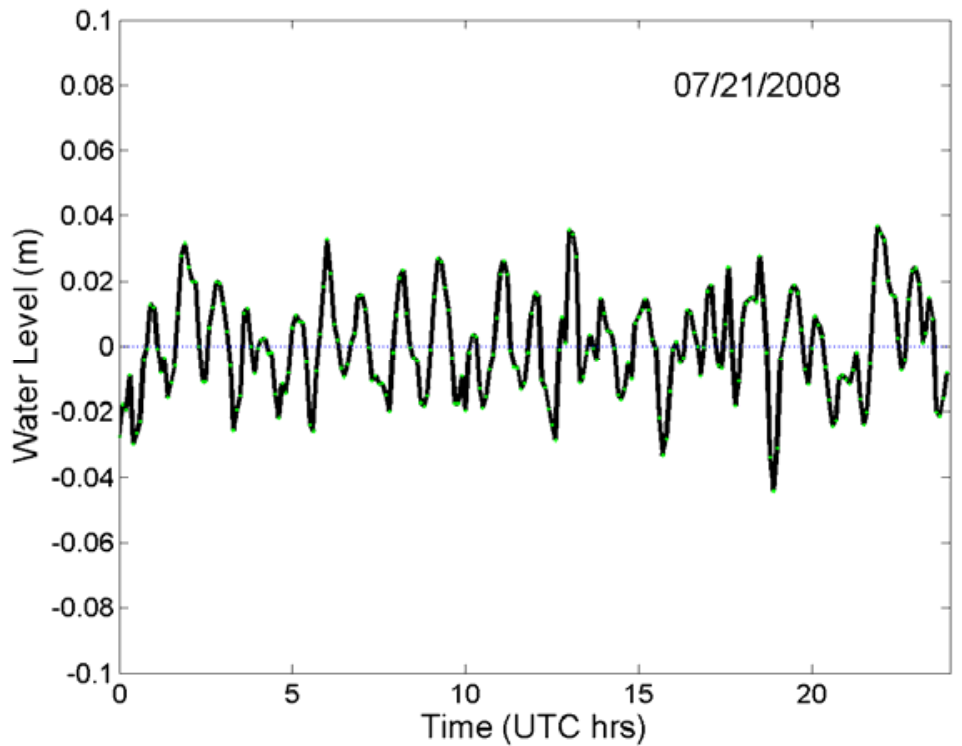

Figure 16. Water level (with the tide removed) at the tide gauge station L.A. Berth 60 in LA/LB Harbor on July 21, 2008. 


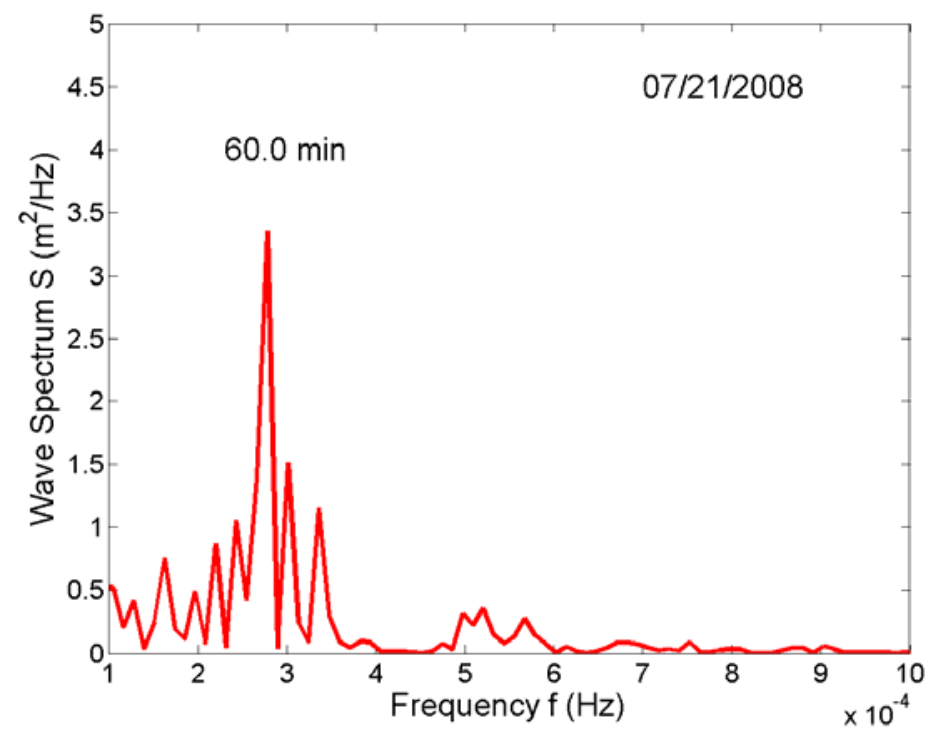

Figure 17. Wave spectrum at the tide gauge station LA Berth 60 in LA/LB Harbor on July 21, 2008.

\section{Conclusion}

As demonstrated in the present study, if the characteristic length of a bay or a harbor is on the same order of magnitude of the wave length associated with an important mode of oscillation then large resonant motions can result. Therefore, the larger the bay or harbor, the larger the important wave lengths (or wave periods) for the maximum resonant oscillation. The large tidal ranges observed in Bay of Fundy are the result of tide-induced resonant motion with a wave period of 12.42 hours. At Crescent City Harbor, California (which is a much smaller harbor), the energy present in the incident tsunamis at periods on the order of 21 to 22 minutes appears to excite the fundamental mode of resonance in that harbor - one of the most important causes of significant tsunami damage there. At LA/LB Harbor in southern California, waves around $1 \mathrm{hr}$ are amplified due to the fundamental resonant mode of oscillation at this wave period. These resonant modes are shown to exist in field measurement records on days of normal condition or during those days associated with tsunami-genic events.

\section{REFERENCES}

Berkhoff, J.C.W. 1972. Computation of combined refraction-diffraction, Proc. 13th Coast. Eng. Conf., ASCE, New York, N.Y., 471-490.

Garrett, C. 1972. Tidal resonance in the Bay of Fundy and Gulf of Maine. Nature, 238, 441-443.

Garrett, C. 1974. Normal resonance in the Bay of Fundy and Gulf of Maine. Can. J. Earth Sci., Vol. 4, 549-556.

Greenberg, D.A. 1979. A numerical model investigation of tidal phenomena in the Bay of Fundy and Gulf of Maine. Marine Geodesy, Vol. 2, No. 2, 161-187.

Lee, J.J. and X.Y. Xing. 2008. Computer modeling for harbor planning and design, Handbook of Coastal and Ocean Engineering (Edited by Y.C. Kim), World Scientific, 695-722.

Lee, J.J., X.Y. Xing, and O. Magoon. 2008. Uncovering the basin resonance at Crescent City Harbor region, Proceedings of ICCE 2008, Vol.2, 1210-1222.

Marmer, H.A. 1922. Tides in the Bay of Fundy, Geographical Review, Vol. 12, No. 2, 195-205.

Proudman, J. 1953. Dynamical oceanography, Methuen-Wiley, London, 409 pp.

Rao, D.B. 1968. Natural oscillations of the Bay of Fundy. J. Fish. Res. Bd. Can., Vol. 25, 1097-1114.

Xing, X.Y., J.J. Lee, and F. Raichlen. 2008. Comparison of computed basin response at San Pedro Bay with long period wave records, Proceedings of ICCE 2008, Vol.2, 1223-1235. 